\title{
Relationships of the Polarisability with the Number of Valence Electrons, the Total Energy and the Second Hyperpolarisability of Methylbenzenes
}

\author{
J. Waite and M. G. Papadopoulos \\ National Hellenic Research Foundation, Athens, Greece \\ Z. Naturforsch. 44a, $591-593$ (1989); received March 31, 1989
}

\begin{abstract}
The total energy and polarisability of 12 methylbenzenes have been computed by employing the CHF-PT-EB-CNDO method. The relationships between the normalized polarisability, the total energy, the second hyperpolarisability and the number of valence electrons of the studied compounds are discussed. Variations in the polarisation properties induced by structural changes are also commented upon.
\end{abstract}

\section{Introduction}

It is known that there is an ever increasing need for materials with large non-linear optical properties [1], because such materials may be used in optical information processing, telecommunication etc. [2]. The search for such molecules is greatly facilitated by elucidating the factors which influence the linear and especially the non-linear electric properties, as well as by revealing the relationships which connect them with other lower order and better understood properties. Thus it is considered useful to comment on the relationships which connect the molecular polarisabilities of the methylbenzenes with the number of valence electrons and the total energy. Subsequently the relationship of the polarisability $(\alpha)$ with the second hyperpolarisability $(\gamma)$ is discussed. This quantitative expression allows a deeper insight into the common trends existing between $\alpha$ and $\gamma$. These relationships have been investigated by employing methylbenzenes as test models, since these molecules, with their regular changes, facilitate the quantification of the observations.

For the computation of the properties, the CHFPT-EB-CNDO $[3,4]$ method (a brief description of which is given in the Appendix) has been used with the following basis sets:

(a) ring carbon and hydrogen [5]:

C: $2 \mathrm{~s}(1.625), 2 \mathrm{p}(1.625)$

$\mathrm{H}: 1 \mathrm{~s}(0.9), 2 \mathrm{~s}(0.4223), 2 \mathrm{p}(0.4223)$

Reprint requests to Dr. M. G. Papadopoulos, National Hellenic Research Foundation, 48, Vas. Constantinou Ave., 11635 Athens, Greece (b) methyl carbon and hydrogen [3a]:

$$
\begin{aligned}
& \mathrm{C}: 2 \mathrm{~s}(1.625), 2 \mathrm{p}(1.625) \\
& \mathrm{H}: 1 \mathrm{~s}(1.0), 2 \mathrm{~s}(0.5), 2 \mathrm{p}(0.5) .
\end{aligned}
$$

These orbitals have been shown to give polarisability and hyperpolarisability results in good agreement with experimental values for several molecules, having a structure related to that of the molecules considered here $[3 \mathrm{~d}, 6 \mathrm{a}]$. Furthermore, for the properties presented we have used normalized values (with respect to the relevant properties of benzene) in order to minimize the effect of any systematic errors due to the approximate nature of the employed method. The relationships involve average values taken over the various isomers of a compound and denoted by $\bar{E}^{\prime}, \bar{\alpha}^{\prime}$ and $\bar{\gamma}^{\prime}$.

The valence electrons are those which mainly determine the magnitude of the linear and non-linear properties. In addition, since the CNDO-type methods, explicitly, use only these electrons, a more quantitative connection, between the polarisability and $n$ (the number of these electrons) was sought. From the present results it is inferred that there is a linear relationship between $\bar{a}^{\prime}$ and $n$ (Fig. 1):

$$
\bar{a}^{\prime}=0.058 n-0.674 \text {. }
$$

In methylbenzenes the number of $\pi$ electrons remains constant (6). However, substitution of $\mathrm{H}_{\text {by }} \mathrm{CH}_{3}$ leads to an increase of the $\sigma$ electrons. Thus the methylbenzenes are dominated by the $\sigma$ electrons to which, to a great extent, the linear relationship between $\bar{\alpha}^{\prime}$ and $\bar{E}^{\prime}$ is attributed. It is added that a linear relationship has been found between $\bar{\alpha}^{\prime}$ and $\bar{E}^{\prime}$ (Fig. 2):

$$
\bar{\alpha}^{\prime}=1.765 \bar{E}^{\prime}-0.690 \text {. }
$$

Progressive methylation leads to structural changes, which induce a greater change in $\bar{\alpha}^{\prime}$ than in $\bar{\gamma}^{\prime}$. 


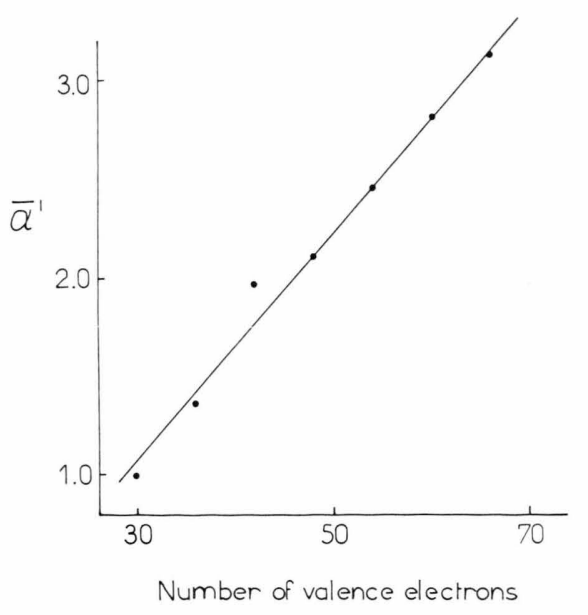

Fig. 1. Plot of $\bar{\alpha}^{\prime}$ vs. the number of valence electrons. For the corresponding compounds cf. Table 1.

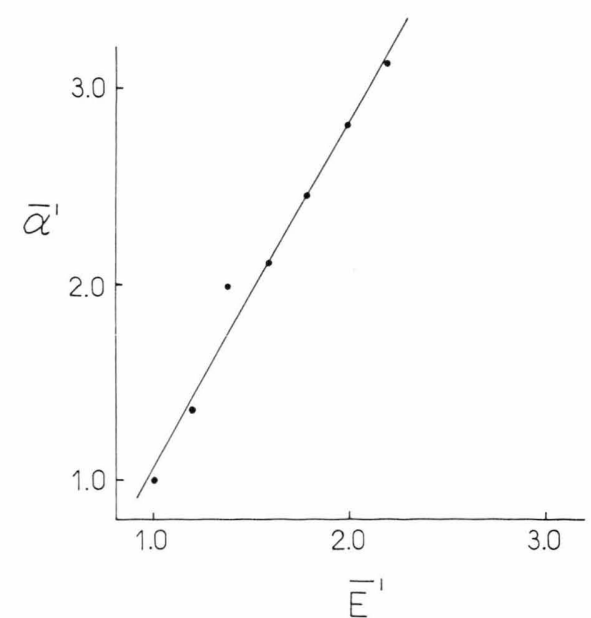

Fig. 2. Plot of $\bar{\alpha}^{\prime}$ vs. $\bar{E}^{\prime}$.

Table 1 . The total energy $E^{\prime}$, polarisability $\alpha^{\prime}$, second hyperpolarisability $\gamma^{\prime}$, and the corresponding normalized average of the methylbenzenes ${ }^{\mathrm{a}}$.

\begin{tabular}{|c|c|c|c|c|c|c|c|}
\hline Compound $^{\mathrm{b}}$ & $n$ & $E^{\prime}$ & $\bar{E}^{\prime}$ & $\alpha^{\prime}$ & $\bar{\alpha}^{\prime}$ & $\gamma^{\prime c}$ & $\bar{\gamma}^{\prime}$ \\
\hline Benzene & 30 & 1.00 & 1.00 & 1.00 & 1.00 & 1.00 & 1.00 \\
\hline Methylbenzene & 36 & 1.1964 & 1.1964 & 1.36 & 1.36 & 1.28 & 1.28 \\
\hline $\begin{array}{l}\text { 1,2-dimethylbenzene } \\
\text { 1,3-dimethylbenzene } \\
\text { 1,4-dimethylbenzene }\end{array}$ & 42 & $\begin{array}{l}1.3946 \\
1.3928 \\
1.3928\end{array}$ & $\begin{array}{c}1.3934 \\
(0.13 \%)\end{array}$ & $\begin{array}{l}2.11 \\
2.01 \\
1.79\end{array}$ & $\begin{array}{c}1.97 \\
(16.2 \%)\end{array}$ & $\begin{array}{l}1.68 \\
1.71 \\
1.50\end{array}$ & $\begin{array}{c}1.63 \\
(12.9 \%)\end{array}$ \\
\hline $\begin{array}{l}\text { 1,3,5-trimethylbenzene } \\
\text { 1,2,3-trimethylbenzene } \\
\text { 1,2,4-trimethylbenzene }\end{array}$ & 48 & $\begin{array}{l}1.5893 \\
1.5930 \\
1.5911\end{array}$ & $\begin{array}{c}1.5911 \\
(0.23 \%)\end{array}$ & $\begin{array}{l}2.20 \\
2.02 \\
2.12\end{array}$ & $\begin{array}{l}2.11 \\
(8.53 \%)\end{array}$ & $\begin{array}{l}1.87 \\
1.65 \\
1.71\end{array}$ & $\begin{array}{c}1.74 \\
(12.6 \%)\end{array}$ \\
\hline $\begin{array}{l}\text { 1,2,4,5-tetramethylbenzene } \\
\text { 1,2,3,4-tetramethylbenzene } \\
1,2,3,5 \text {-tetramethylbenzene }\end{array}$ & 54 & $\begin{array}{l}1.7893 \\
1.7913 \\
1.7894\end{array}$ & $\begin{array}{c}1.7900 \\
(0.11 \%)\end{array}$ & $\begin{array}{l}2.50 \\
2.40 \\
2.49\end{array}$ & $\begin{array}{l}2.46 \\
(4.07 \%)\end{array}$ & $\begin{array}{l}1.88 \\
1.81 \\
1.92\end{array}$ & $\begin{array}{l}1.87 \\
(5.88 \%)\end{array}$ \\
\hline pentamethylbenzene & 60 & 1.9825 & 1.9825 & 2.81 & 2.81 & 2.00 & 2.00 \\
\hline hexamethylbenzene & 66 & 2.1898 & 2.1898 & 3.13 & 3.13 & 2.14 & 2.14 \\
\hline
\end{tabular}

a The polarisability $\alpha$ and the hyperpolarisability $\gamma$ are given by [9]

$\alpha=\frac{1}{3}\left(\alpha_{x x}+\alpha_{y y}+\alpha_{z z}\right)$,

$\gamma=\frac{1}{5}\left(\gamma_{x x x x}+\gamma_{y y y y}+\gamma_{z z z z}+2 \gamma_{x x y y}+2 \gamma_{x x z z}+2 \gamma_{y y z z}\right)$,

where $x, y, z$ denote Cartesian components.

The reported values have been normalized with respect to the corresponding values of benzene. The per-cents, in parentheses, correspond to the maximum difference between the properties of the isomers of a given compound, with respect to the average value.

b The coordinates of the molecules have been determined employing data from [10].

c The absolute values of the second hyperpolarisabilities of methylbenzenes are from [11].

Furthermore, the latter property has a rate of change similar to that of $\bar{E}^{\prime}$. On the other hand $\bar{P}^{\prime}(\max ) /$ $\bar{P}^{\prime}(\mathrm{min})$ are 2.19 and 2.14 for $\bar{P}^{\prime}$ being $\bar{E}^{\prime}$ and $\bar{\gamma}^{\prime}$, respectively. The above observations are very interesting, considering that, in general, the second hyperpolarisability is much more sensitive than the energy to changes in the molecular structure.

A more comprehensive understanding of the structural effects on the properties is provided by consider- ing the variation of the properties within each group of isomers. It is then observed (Table 1) that $\gamma^{\prime}$ is slightly more influenced than $\alpha^{\prime}$, but both properties are affected considerably more than $\bar{E}^{\prime}$. Steric effects are considered to contribute to the differentiation of the properties of the isomers of each compound. In Table 1 we give, in per-cent (with respect to the average value) the maximum difference between the properties of the isomers of a given compound. 


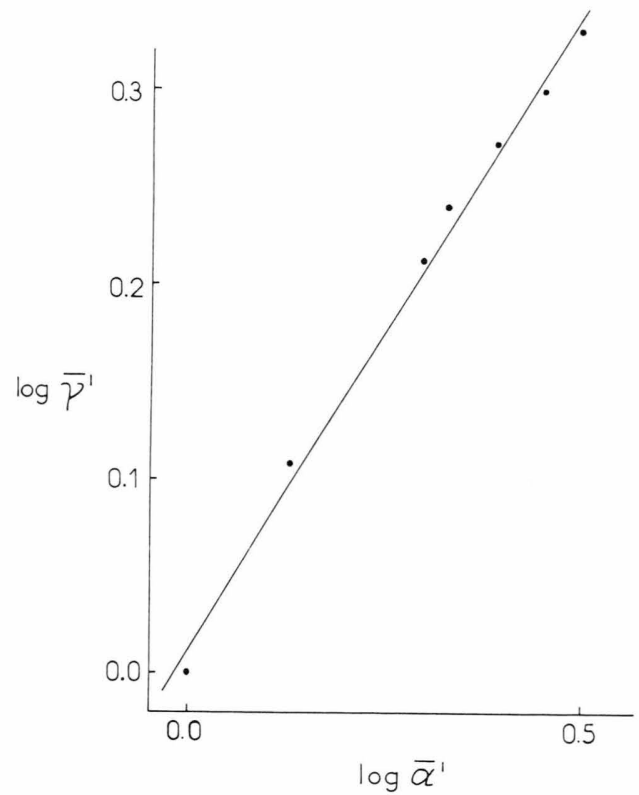

Fig. 3. Plot of $\log \bar{\gamma}^{\prime}$ vs. $\log \bar{\alpha}^{\prime}$.

We find that the relationship between $\bar{\gamma}^{\prime}$ and $\bar{\alpha}^{\prime}$ is parabolic as demonstrated (Fig. 3) by the linear relationship between $\log \bar{\gamma}^{\prime}$ and $\log \bar{\alpha}^{\prime}[6 \mathrm{~b}]$. The empirical equation which results from least squares curve fitting is given by

$$
\bar{\gamma}^{\prime}=C_{1}\left(\bar{\alpha}^{\prime}\right)^{C_{2}},
$$

where

$$
C_{1}=1.028, \quad C_{2}=0.661 .
$$

In summary, the present results reveal that the polarisability $\left(\bar{\alpha}^{\prime}\right)$ of methylbenzenes is connected to $n$

[1] J. Badan, R. Hierle, A. Périgaud, and J. Zyss, Nonlinear Optical Properties of Organic and Polymeric Materials, p. 81, Edited by D. J. Williams, ACS Symposium Series 233, American Chemical Society, Washington DC 1983.

[2] D. J. Williams, Preface of the book cited in [1].

[3a] C. A. Nicolaides, M. Papadopoulos, and J. Waite, Theor. Chim. Acta 61, 427 (1982).

[3 b] M. G. Papadopoulos, J. Waite, and C. A. Nicolaides, J. Chem. Phys. 77, 2527 (1982).

[3c] J. Waite, M. G. Papadopoulos, and C. A. Nicolaides, J. Chem. Phys. 77, 2536 (1982).

[3d] J. Waite and M. G. Papadopoulos, J. Chem. Phys. 82, 1427 (1985)

[4] J. Waite and M. G. Papadopoulos, J. Chem. Soc. Faraday Trans. II, 81, 433 (1985).

[5] J. Waite and M. G. Papadopoulos, J. Comp. Chem. 4, 578 (1983).

[6a] M. G. Papadopoulos and J. Waite, J. Phys. Chem. 90, 5491 (1986).

[6 b] L. H. Johnson, Nomography and empirical equations, John Wiley, London 1952. and $\bar{E}^{\prime}$ by a linear relationship, while $\bar{\alpha}^{\prime}$ is connected to $\bar{\gamma}^{\prime}$ by a parabolic equation. The reported analysis contributes to the elucidation of the structure-polarisation relationship, which is of cardinal importance for the design of materials with the appropriate properties for specific applications (e.g. devices in nonlinear optics)

\section{Appendix}

The CHF-PT-EB-CNDO method [3, 4], which had been used for the computation of the properties reported here relies on

a) An extended basis (EB) CNDO [7] wave function,

b) McWeeny's et al. [8] coupled Hartree-Fock perturbation theory (CHF-PT).

The computation of the coordinates has been performed by employing a polar-to-cartesian conversion subroutine similar to that available in Dewar's MINDO and MNDO programs (QCPE 309 and 353). The SCF part of the program is an extended and upgraded version of the $\mathrm{CNDO} / 2$ program $(\mathrm{QCPE}$ 141).

For the computations of the density matrices the following criteria have been used:

$$
\left|{ }_{k} R_{i j}^{(m)}-{ }_{(k-1)} R_{i j}^{(m)}\right|<10^{-n} N,
$$

where $k$ is the iteration number, $m$ is the order of the density matrix $R$, and $N$ is the number of orbitals. We have for every $i j$

$$
\begin{array}{ll}
\text { for } m=0: & n=4, \\
\text { for } m=1,2: & n=6 .
\end{array}
$$

[7 a] J. A. Pople and D. L. Beveridge, Approximate Molecular Orbital Theory, McGraw Hill, New York 1970.

[7 b] H. Shinoda and T. Akutagawa, Bull. Chem. Soc. Japan 48, 3431 (1975).

[8] R. McWeeny, Phys. Rev. 126, 1028 (1962); G. Diercksen and R. McWeeny, J. Chem. Phys. 44, 3554 (1966); J. L. Dodds, R. McWeeny, W. T. Raynes, and J. P. Riley, Mol. Phys. 33, 611 (1977).

[9a] A. D. Buckingham and B. J. Orr, Q. Rev., Chem. Soc. 21, 195 (1967).

[9b] M. P. Bogaard and B. J. Orr, MTP International Review of Science, Physical Chemistry Series Two, Molecular Structure and Properties, Vol. 2, p. 149, Edited by A. D. Buckingham, Butterworths, London 1975.

[10] Table of Interatomic Distances and Configurations in Molecules and Ions, edited by L. E. Sutton, Special Publication No.18, The Chemical Society, London 1965.

[11] M. G. Papadopoulos and J. Waite, J. Chem. Soc., Perkin Trans. II, 2055 (1988). 